\title{
Unexpected migration of a benzoyl group in the intramolecular Wittig reaction of 0 -acyloxybenzylidenephosphoranes with benzoyl chlorides: One-pot synthesis of isomeric 3-benzoyl-2-phenylbenzofurans
}

\author{
Michela Begala ${ }^{\mathrm{a}, *, 1}$, Michele Mancinelli ${ }^{\mathrm{b}}$, Giovanna Lucia Delogu ${ }^{\mathrm{a}, 1}$ \\ ${ }^{a}$ Department of Life and Environmental Sciences, University of Cagliari, Via Ospedale 72, 09124 Cagliari, Italy \\ ${ }^{\mathrm{b}}$ Department of Industrial Chemistry “Toso Montanari", University of Bologna, Viale del Risorgimento, 4, 40136 Bologna, Italy
}

\section{A R T I C L E I N F O}

\section{Article history:}

Received 18 November 2019

Revised 10 January 2020

Accepted 14 January 2020

Available online 20 January 2020

Keywords:

Wittig reaction

Phosphoranes

2-Phenylbenzofurans

3-Aroylbenzofurans

\begin{abstract}
A B S T R A C T
The reaction of 0 -acyloxybenzylidenetriphenylphosphoranes with substituted benzoyl chlorides in an aprotic solvent led, together with the expected 2-phenylbenzofuran, to isomeric 3-benzoyl-2-phenylbenzofuran derivatives. This result formally corresponds to intramolecular migration of the benzoyl group from the ortho oxygen atom to the ylide carbanion via cyclization and ring opening of the starting $o$-acyloxybenzylidenetriphenylphosphoranes.
\end{abstract}

๑) 2020 Elsevier Ltd. All rights reserved.

\section{Introduction}

3-Aroyl $[b]$ benzofurans are present in the structural cores of a large number of bioactive molecules in current pharmaceutical use and development (Fig. 1) [1-4]. As a result, numerous approaches towards the synthesis of 3-acylbenzofurans have been disclosed in the literature [5,6]; however, most of them are only suitable for the preparation of 2-aroyl-3-benzoylbenzofuran derivatives bearing electron-donating groups [7].

In our previous work, we found that the reaction of 2-hydroxybenzyltriphenylphosphonium bromide with benzoyl chlorides and triethylamine in an aprotic solvent (i.e. toluene), leads to 3-benzoyl-2-phenylbenzo[b]furans via ylide acylation in addition to the expected 2-phenylbenzofurans (Scheme 1) [8,9].

Hercouet and Le Corre [10] reported that the intramolecular Wittig reaction of 0 -acyloxybenzylidenetriphenylphosphoranes leads to the corresponding benzofurans in aprotic medium (toluene) or to acylated products in protic medium $(t-\mathrm{BuOH})$. Therefore, we became interested in verifying whether the $o$-[(benzoyloxy)benzyl]-triphenyl-phosphorane was the key intermediate leading to the 3-benzoyl derivatives. Our results showed that

\footnotetext{
* Corresponding author.

E-mail address: michelabegala@unica.it (M. Begala).

1 These authors contributed equally to the work.
}

benzoyl chloride reacts with phosphorane I to give a mixture of 2-phenylbenzofuran and 3-benzoyl-2-phenylbenzofuran, thus confirming this hypothesis (Scheme 2).

3-Benzoyl-2-phenylbenzofuran derivatives with strongly electron-withdrawing groups (e.g. $\mathrm{NO}_{2}$ and $\mathrm{CN}$ ) on the 2-phenyl or 3-benzoyl ring, could provide convenient intermediates in the preparation of more complicated compounds [11]. However, no methods for the synthesis of such deactivated benzofurans have been described. For instance, during the Friedel-Crafts acylation of 2-phenylbenzofuran with nitrobenzoyl chloride, other positions of the benzofuran ring were also acylated, leading to a complex mixture of regioisomers where the expected derivative was formed as a minor product [12]. Thus, the development of new synthetic routes, especially those that allow access to deactivated analogues, is of considerable interest.

In this context, we envisaged that the reaction of $o$-acyloxybenzylidenetriphenylphosphoranes with substituted benzoyl chlorides would provide access to the corresponding 3-benzoyl-2-phenylbenzofurans bearing different substituents on the 2-phenyl and/or the 3-benzoyl ring.

In the present work, we describe our efforts toward the synthesis of diversely 2,3-disubstituted benzofurans with particular attention given to the preparation of 3-benzoyl-2-phenylbenzofuran derivatives bearing electron-withdrawing groups. Moreover, the unexpected formation of the 3-acyl isomers, prompted us to further investigate the Wittig reaction. 
<smiles>CCCCc1oc2ccccc2c1C(=O)c1cc(I)c(OCCN(CC)CC)c(I)c1</smiles><smiles>COc1ccc(-c2oc3cc(OC)ccc3c2C(=O)c2ccc(C#N)cc2)cc1</smiles>

amiodarone (A)

LY-320135 (B)<smiles>CCc1oc2ccccc2c1C(=O)c1cc(Br)c(O)c(Br)c1</smiles>

benzbromarone $(\mathbf{C})$

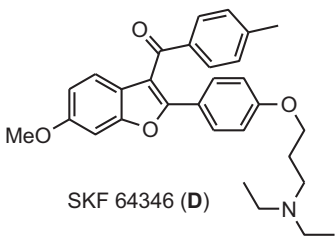

Fig. 1. Representative 3-aroyl $[b]$ benzofurans of pharmacological interest.

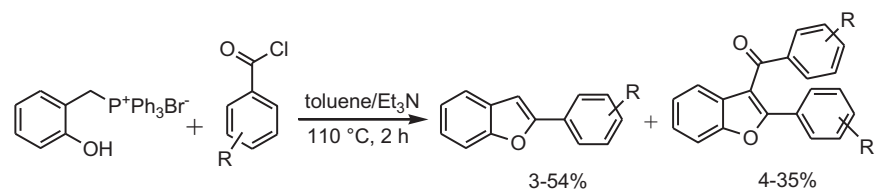

Scheme 1. Synthetic route towards 2-phenylbenzofurans and 3-benzoyl-2phenylbenzofurans.<smiles>O=C(Oc1ccccc1CPc1ccccc1)c1ccccc1</smiles><smiles>CCOC(C)(C)NC(C)(C)C</smiles><smiles>c1ccc(-c2cc3ccccc3o2)cc1</smiles><smiles>O=C(c1ccccc1)c1c(-c2ccccc2)oc2ccccc12</smiles>

Scheme 2. Formation of 2-phenylbenzofuran and 3-benzoyl-2-phenylbenzofuran from $\mathbf{I}$.

\section{Results and discussion}

o-[(Benzoyloxy)benzyl]-triphenyl-phosphoranes I, prepared from ortho-cresol $[8,13,14]$ (Scheme 3), were reacted with benzoyl

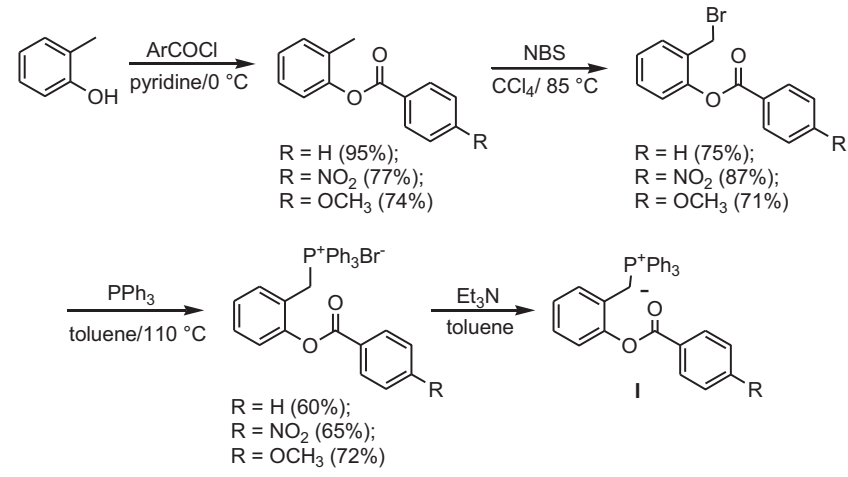

Scheme 3. Synthetic route towards o-[(benzoyloxy)benzyl]-triphenyl-phosphoranes $\mathbf{I}\left(\mathrm{R}=\mathrm{H}, \mathrm{NO}_{2}, \mathrm{OCH}_{3}\right)$.

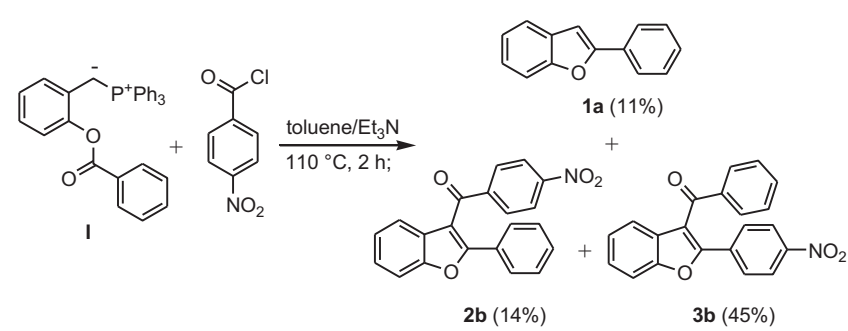

Scheme 4. Synthesis of isomeric compounds $\mathbf{2 b}$ and $\mathbf{3 b}$.

chlorides substituted with electron withdrawing or donating groups.

When I $(\mathrm{R}=\mathrm{H})$ was reacted with 4-nitrobenzoyl chloride in the presence of triethylamine in toluene, the reaction mixture showed the formation of two 3-acyl isomers (Scheme 4), i.e. the expected 3(4-nitrobenzoyl)-2-phenylbenzofuran 2b and 3-benzoyl-2-(4nitrophenyl)benzofuran $\mathbf{3 b}$, as identified by NMR spectroscopy and GC/MS analysis.

The same behaviour was also observed when a variety of 4-substituted benzoyl chlorides were used (vide infra). These results clearly suggest that benzoyl group migration occurred to some extent. Interestingly, Hercouet and Le Corre reported such a

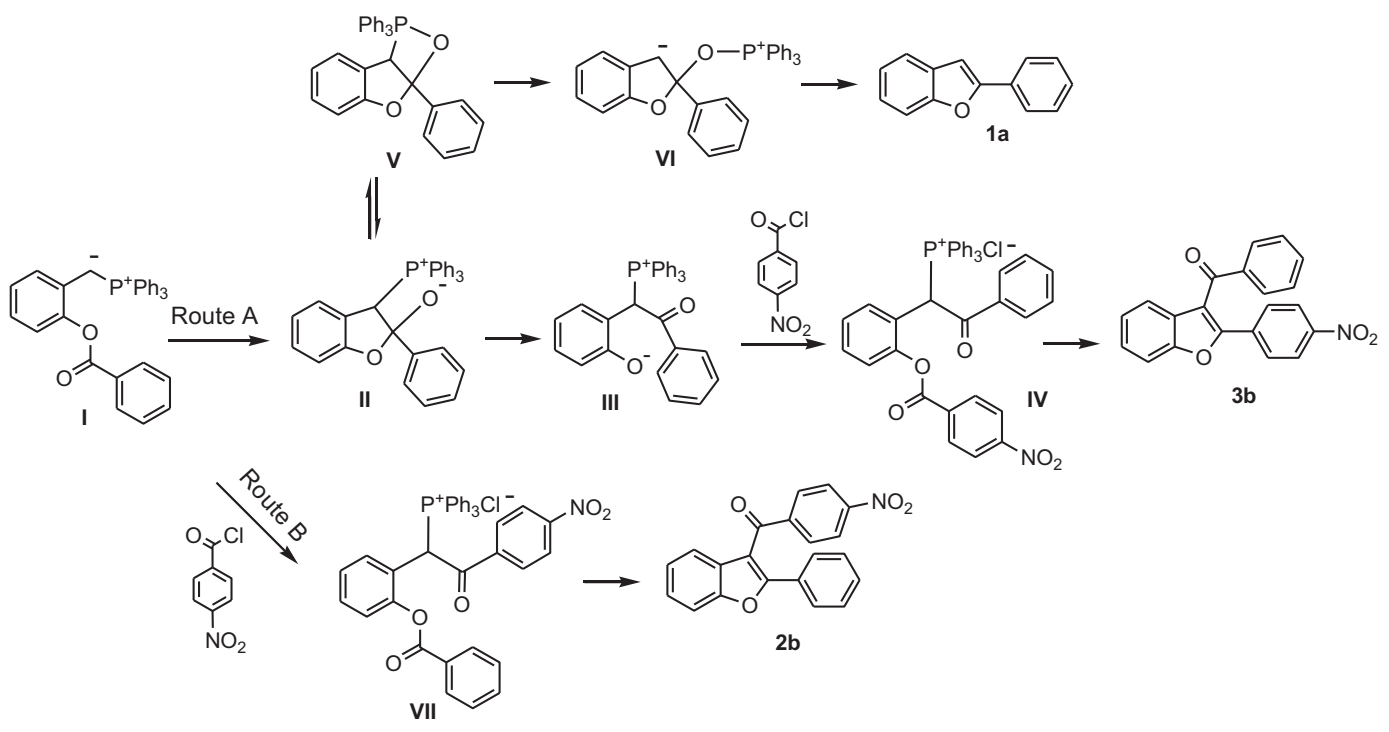

Scheme 5. Proposed mechanism of benzoyl group migration from ylide $\mathbf{I}$ and the formation of isomeric compounds $\mathbf{2 b}$ and $\mathbf{3 b}$. 
transposition only under protic condition $(t-\mathrm{BuOH})$ and using a strong base ( $t$-BuOK) [10]. An analogous 1,5-transposition of an ester acyl functional group was also observed by Gorgues and coworkers for the $\sigma$-bonded organochromium(III) complex resulting from the reduction of ortho-bromomethylphenyl benzoate with $\mathrm{CrCl}_{2}$ [15].

A plausible mechanism is depicted in Scheme 5. Carbanion I reacts with the corresponding acyl chloride to give the isomer $\mathbf{2 b}$ (Route B), as previously proposed by us [8]. Alternatively, the Oacylated phosphorane I can also cyclize directly into intermediate II (Route A) to give either the 2-phenylbenzofuran 1a or undergo ring-opening to the C-acylated phenolate III. Intermediate III is $\mathrm{O}$-acylated to give the phenol ester IV, that leads to the isomeric 3-benzoyl-2-phenylbenzofuran $\mathbf{3 b}$ via a ylide intermediate.

Interestingly, the isomer arising from benzoyl migration $\mathbf{3 b}(45 \%)$ was the main product; therefore Route A was more favored than Route B. These data clearly indicate that the O-acylated phosphorane I spontaneously cyclizes into II, presumably because intramolecular attack of the ylide carbanion to the ortho carbonyl group is favoured by their proximity (Scheme 5 and Table 1, entry 1 ).

This behaviour was even more pronounced when 4-nitrobenzoyl chloride was replaced by 4-methoxybenzoyl chloride (Table 1 ,

Table 1

Synthetic route towards 2-phenylbenzofurans 1a-c, and 3-benzoyl-2-phenylbenzofurans 2-9a-e, 10 and $11 .^{\text {a }}$

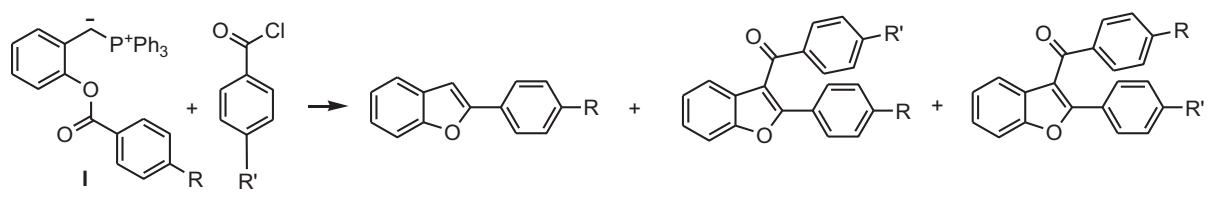

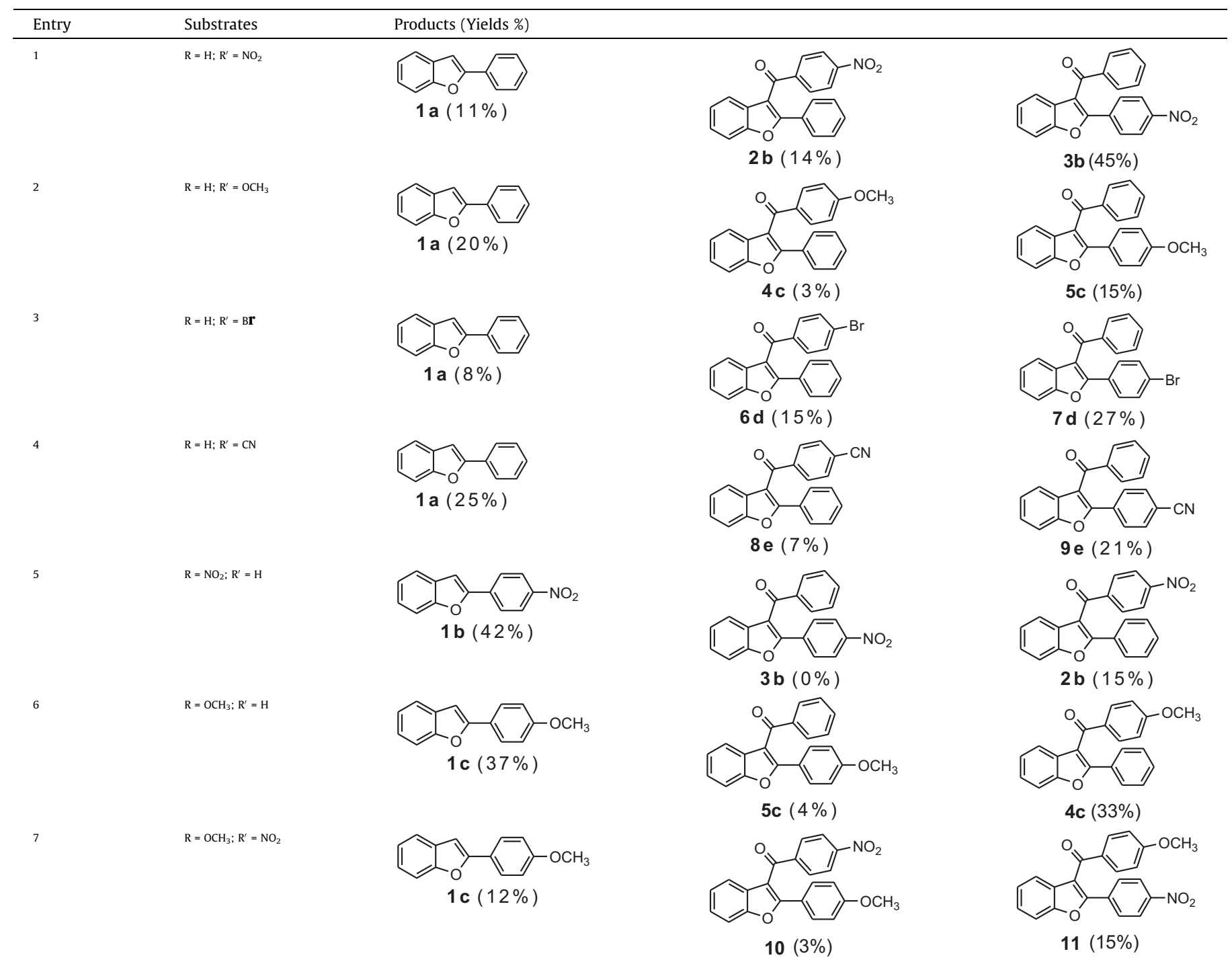

${ }^{\mathrm{a}} \mathrm{I}$ ( 1 equiv.), benzoyl chlorides ( 2.5 equiv.), $\mathrm{Et}_{3} \mathrm{~N}$ (2.5 equiv.), toluene $110{ }^{\circ} \mathrm{C}, 2 \mathrm{~h}$. 
entry 2). In the latter case, the reaction of I with the less electrophilic 4-methoxybenzoyl chloride (Route B) was suppressed (4c, 3\%) in favour of Route A (1a, 20\%; 5c, 15\%). These results clearly indicate that deactivated benzoyl chlorides allow the formation of both isomeric 3-acyl derivatives, most likely because I and III rapidly attack the highly electrophilic carbonyl of the 4nitrobenzoyl chloride. Accordingly, analogous trends were also observed with 4-bromo and 4-cyanobenzoyl chlorides (Table 1, entries 3 and 4).

When substituted 0 -[(benzoyloxy)benzyl]-triphenyl-phosphoranes were used $\left(\mathrm{R}=\mathrm{NO}_{2}, \mathrm{OCH}_{3}\right.$, entries 5 and 6$)$, we observed that the electron withdrawing group further suppressed Route $B$ in favour of cyclization to II (Route A), as reflected by the higher yield of 2-(4-nitrophenyl)benzofuran $\mathbf{1 b}(42 \%)$ and the absence of 3-benzoyl-2-(4-nitrophenyl)benzofuran $\mathbf{3 b}$ (Table 1, entry 5). This behaviour could be rationalized by the fact that the 4-nitro group increases the electrophilicity of the carbonyl group of $\mathbf{I}\left(\mathrm{R}=\mathrm{NO}_{2}\right)$, making it easier for the ylide carbanion to attack this electrophilic centre. Accordingly, o-[(benzoyloxy)benzyl]-triphenyl-phosphorane bearing an electron donating group $\left(\mathrm{R}=\mathrm{OCH}_{3}\right)$ still resulted in the formation of isomer $\mathbf{5 c}$; albeit in low yield (4\%) (Table 1 , entry 6).

The reaction of substituted $o$-[(benzoyloxy)benzyl]-triphenylphosphoranes I $\left(\mathrm{R}=\mathrm{OCH}_{3}\right)$ with 4-nitrobenzoyl chloride (Table 1 , entry 7) again leads predominantly to 2-(4-methoxyphenyl)benzofuran 1c (12\%) and isomer 11 (15\%) via Route A.

\section{Conclusion}

Our previous results demonstrated that under aprotic conditions 3-acylbenzofurans can be obtained from the reaction of $o$-[(benzoyloxy)benzyl]-triphenyl-phosphoranes with benzoyl chlorides. We have also demonstrated that under these conditions phosphoranes preferentially undergo intramolecular migration of the benzoyl group via cyclization and ring opening. This behaviour clarifies the unexpected formation of two sets of 3-acylbenzofuran isomers when phosphoranes react with benzoyl chlorides.

In particular, we found that the isomer arising from benzoyl migration is further favoured by the use of deactivated benzoyl chlorides or by phosphoranes I with a 4-methoxy group. This finding is of considerable interest as it allows preparation of a wide variety of 3-acylbenzofuran derivatives which are difficult to obtain using alternative methods.

\section{Declaration of Competing Interest}

The authors declare that they have no known competing financial interests or personal relationships that could have appeared to influence the work reported in this paper.

\section{Acknowledgments}

The present work was partially supported by FIR (Fondo Integrativo per la Ricerca - annualità 2018) - University of Cagliari, Italy.

\section{Appendix A. Supplementary data}

Supplementary data to this article can be found online at https://doi.org/10.1016/j.tetlet.2020.151634.

\section{References}

[1] (a) S.N. Singh, R.D. Fletcher, S.G. Fisher, B.N. Singh, H.D. Lewis, P.C. Deedwania, B.M. Massie, C. Colling, D. Layyeri, N. Eng. J. Med. 333 (1995) 77-82;

(b) T. Kálai, G. Várbió, Z. Bognár, A. Pálfi, K. Hantó, B. Bognár, E. Ősz, B. Smegi, K. Hideg, Bioorg. Med. Chem. 13 (2005) 2629-2636;

(c) R. Hartong, W.M. Wiersinga, T.A. Plomp, Horm. Metab. Res. 22 (1990) 8589;

(d) S. Basaria, D.S. Cooper, Am. J. Med. 118 (2005) 706-714.

[2] C.C. Felder, K.E. Joyce, E.M. Briley, M. Glass, K.P. Mackie, K.J. Fahey, G.J. Cullian, D.C. Hunden, D.W. Johnson, M.O. Chaney, G.A. Koppel, M.J. Brownstein, Pharmacol. Exp. Ther. 284 (1) (1998) 291-297.

[3] R.C. Heel, R.N. Brogden, T.M. Speight, G.S. Avery, Drugs 14 (1977) 349-366.

[4] (a) L.M. Brenner, C.K. Brush. US Pat. 4.001 .426 (1997).;

(b) D.R. Howlett, A.E. Perry, F. Godfrey, J.E. Swatton, K.H. Jennings, C. Spitzfaden, H. Wadsworth, S.E. Wood, R.E. Markwell, Biochem. J. 340 (1999) 283-289.

[5] W. Gong, D. Liu, F. Li, J. Gao, H. Li, J. Lang, Tetrahedron 71 (2015) 1269-1275.

[6] (a) M. Nakamura, L. Ilies, S. Otsubo, E. Nakamura, Org. Lett. 8 (2006) 2803 2805;

(b) J. Zhao, H. Fang, C. Xie, et al., Org. Chem. 2 (2013) 1044-1047;

(c) M.W. Farrar, R. Levine, J. Am. Chem. Soc. 72 (1950) 4433-4436.

[7] (a) K. Oda, M. Machida, Chem. Pharm. Bull. 41 (1993) 1299-1301;

(b) H. Yuan, K. Bi, B. Li, R. Yue, J. Ye, Y. Shen, L. Shan, H. Jin, Q. Sun, W. Zhang, Org. Lett. 15 (2013) 4742-4745:

(c) A. Arcadi, S. Cacchi, M. Del Rosario, G. Fabrizi, F. Marinelli, J. Org. Chem. 61 (1996) 9280-9288;

(d) H. Jason, J.H. Chaplin, B.L. Flynn, Chem. Commun. (2001) 1594-1595;

(e) S.R. Mothe, D. Susanti, P.W. Hong Chan, Tetrahedron Lett. 51 (2010) 2136 2140.

[8] M. Begala, P. Caboni, M.J. Matos, G.L. Delogu, Tetrahedron Lett. 59 (2018) 1711-1714.

[9] M. Begala, G.L. Delogu, J. Mass Spectrom. 54 (9) (2019) 750-760.

[10] (a) A. Hercouet, M. Le Corre, Tetrahedron Lett. 23 (1979) 2145-2148; (b) A. Hercouet, M. Le Corre, Tetrahedron 37 (16) (1981) 2867-2873.

[11] (a) G.W. Kabalka, R.S. Varma, in: Comprehensive Organic Synthesis; Trost BM, Pergamon Press, Oxford, 1991, pp. 363-379;

(b) Z. Rappoport (Ed.), Chemistry of the Cyano Group, John Wiley \& Sons, London, 1970.

[12] (a) L.J. Twyman, D. Allsop, Tetrahedron Lett. 40 (1999) 9383-9384; (b) M. Thévenin, S. Thoret, P. Grellier, J. Dubois, Bioorg. Med. Chem. 21 (17) (2013) 4885-4892.

[13] S. Ghosh, J. Das, Tetrahedron Lett. 52 (2011) 1112-1116.

[14] T. Routasalo, J. Helaja, J. Kavakka, A.M.P. Koskinen, Eur. J. Org. Chem. 18 (2008) 3190-3199.

[15] B. Ledoussal, A. Gorgues, A. Le Coq, Tetrahedron 43 (1987) 5841-5852. 